\title{
HOW MUCH ‘DISTANCE' DOES LANGUAGE CREATE IN ODL MATERIALS? A BOTSWANA CASE STUDY
}

\section{Mmabaledi Kefilwe Seeletso}

Department of Educational Management and Leadership

School of Education

Botswana College of Distance and Open Learning (BOCODOL)

e-mail:mmaba.see@gmail.com

\section{Rinelle Evans}

Department of Humanities Education

Faculty of Education

University of Pretoria

e-mail: rinelle.evans@up.ac.za

\section{ABSTRACT}

It is assumed that open and distance learning institutions develop study materials that adequately engage learners with quality content to assist their content mastery. However, distance learners continue to underperform, which raises the concern that high drop-out and failure rates may be ascribed to the study materials. This mixed-methods case study examined instructional material developed for secondary school learners studying via the open and distance learning mode. The study was informed by Sweller's Cognitive Load Theory to evaluate the process of designing and developing instructional materials while Gorsky, Caspi and Trumper's Theory of Instructional Dialogue was used to map interaction with and within the selected study materials. A self-designed evaluation rubric included languagerelated criteria to gauge the accessibility of content. A questionnaire survey was undertaken with purposively identified participants: five material developers, 176 learners, and six tutors. Six semi-structured group interviews and twenty individual face-to-face interviews were conducted. Open coding and SPSS reports were used for qualitative and quantitative data analysis, respectively. Findings related to non-alignment of materials with learner profile, and the national syllabus, while 
inadequate proficiency in the language of instruction remained problematic. The outcomes of this study highlight the importance of well-trained material developers and focused ODL policies for quality assuring effective content design and development to accommodate diverse learners with limited English proficiency.

Keywords: Cognitive Load Theory; content accessibility; English as language barrier; materials design and development; open and distance learning; Theory of Instructional Dialogue.

\section{INTRODUCTION}

The contribution of open and distance learning (ODL) to educating those unable to afford studying at residential institutions of learning continues to receive attention as various technologies extend its traditional reach. ODL learners are supposedly offered a learning experience which is on par with that of learners in the traditional classroom system, yet their progression is slower and their throughput generally remains low. Institutions pride themselves on the extensive learner support systems and well-crafted study materials they offer to mediate the learning experience, yet the design and development of paperbased learning materials remain an under-researched area, especially in the African context (Indira Gandhi National Open University 2008; Schlosser and Anderson 1994).

In this article we argue that even though printed ODL learning materials may appear to be well designed and adequate in terms of content and quality at first glance, learners do not progress satisfactorily with their studies. We ask whether the instructional materials may possibly prevent learners from fully mastering content and thus achieving eventual academic success. We analysed the design and development of printed ODL learning materials prepared for secondary school learners as provided by the Botswana College of Distance and Open Learning (BOCODOL). We set out to establish whether these materials, with specific reference to the English used as medium of instruction, might keep learners from enjoying a rich learning experience.

\section{CONTEXT AND RATIONALE}

Botswana, as a former British colony, continues to model its education system on that of its earlier sovereign (Molosiwa 2009). The medium of instruction in public primary schools is the national language, Setswana, up to grade 6. Thereafter English is introduced from higher primary up to tertiary level as the sole medium of instruction (Chebanne and Nyathi-Ramahobo 2003; Republic of Botswana 2003; Jotia and Pansiri 2013).

Botswana's national philosophy of education upholds the principles of democracy, development, self-reliance, unity and botho (humanness) (Republic of Botswana 1993). These principles are further alluded to in the country's national vision - 'Towards 
Prosperity for All' - commonly known as Vision 2016 (Republic of Botswana 1997) as well as the Millennium Development Goals (MDGs).

Vision 2016 outlines critical areas in which Botswana has been striving to make significant improvements by the time the country celebrates fifty years of independence in 2016. One of the priorities Botswana set in Vision 2016 is to have an educated and informed citizenry (Republic of Botswana 1997). One means of achieving this is ODL, which is currently accessible to all people irrespective of gender, age or academic history. This mode of study has become a governmental priority, especially as most employers are no longer able to afford employees leave for full-time study as replacements are expensive (Mphinyane 1999). Furthermore, many people are not prepared to leave their families for extended periods of time (Seeletso 2011).

The Ministry of Education has been managing various initiatives to develop education both in the formal and non-formal sectors since the early 1970s (Republic of Botswana 1977; Republic of Botswana 1993; Mphinyane 1999). BOCODOL was established by legislation in December 1998 to enable the provision of quality education through the ODL mode to those who could not, for whatever reason, attend a traditional institution as a full-time learner. BOCODOL now has five regional offices in major towns, namely Gaborone, Palapye, Francistown, Maun and Kang, with community study centres where face-to-face support sessions are conducted. Local school classrooms serve as meeting sites for ODL classes between 17:00 and 20:00.

BOCODOL is mandated to offer secondary school distance learners exactly the same curriculum as is taught to conventional learners through what is called school equivalency programmes. Such programmes offer subjects that conventional classroom learning (CCL) offers at levels required for the Junior Certificate Examination (JCE) and Botswana General Certificate of Secondary Education (BGCSE). Offering distance learners and conventional students the same curriculum and examinations ought to provide ODL and CCL learners with the same career opportunities upon completion of their studies. This therefore makes distance learning course materials very important since they are the main source of instruction, and consequently a key contributor to the envisaged performance and progression of learners. Yet, despite being taught the same curriculum as conventional learners, ODL learners experience unique challenges related to studying via the distance mode. These include the isolation of studying alone due to geographical separation from other learners, and lacking a teacher's audible, expressive voice and interactive style of teaching. Participants also felt no sense of belonging in ODL, as the face-to-face sessions are not even compulsory (Seeletso 2015).

In recent years, there has been an upward trend of learners either abandoning their studies before completion of the programme of study or failing to perform satisfactorily during the examination (BOCODOL 2010/2011). Several studies have suggested possible contributing factors to the unimpressive academic performance by BOCODOL learners. Gatsha (2010) states that learning support is compromised at BOCODOL, amongst other things, by a need for closer monitoring of how tutors execute their duties 
to ensure that learners do not disengage and finally terminate their studies. Gatsha $(2010,140)$ also found that the materials used by secondary school students enrolled with BOCODOL were not developed 'for $2^{\text {nd }}$ language speakers of English and not for learners from marginalised communities'. The materials made reference to topics or objects that learners from pastoral communities had no exposure to.

Otukile (2011) concurs with Gatsha that distance learners are not given the support they need to help them fully embrace the ODL philosophy i.e. to move from CCL mode into the unfamiliar environment of ODL. He asserts that ODL institutions need to help their learners understand that their 'teacher is supposed to be in print' (Otukile 2011, 66). This, he writes, should be made clear, as he observed that there were tutors 'who absent themselves... and learners were frustrated by lack of a permanent presence of a teacher' (Otukile 2011, 67). Though Gatsha's and Otukile's studies provide valuable insights, their focus was learner support and how its absence or mismanagement negatively affected learners' academic progress. Our study draws on their findings but extends the quality criteria for ODL study materials by calling attention to the type of language used, which ought to assist distance learners in 'hearing' their 'teacher' provide instructions, counselling and feedback to them through the text (Rowntree 1990).

Although Phillips (2007), Reed (2010), Sibomana (2014) and Stewart and Lopes (2015) have contributed substantial research regarding ODL learning materials, little is known about the efficacy of materials developed for school equivalency programmes. Our study considered materials developed for the BGCSE programme, which is the point of entry for tertiary education. The course materials were written in English, the language of instruction at this level. If the claim as stated in the Revised National Education Policy (RNEP) of 1994 that ODL learners have the same potential as CCL learners is valid, then by implication, ODL learners should perform well enough to continue with their tertiary education as many CCL learners do. This, however, is not the case at BOCODOL as the throughput rate is much lower than that of CCL learners, as shown in the table below.

Table 1: English Language results for ODL learners (2012-2014)

\begin{tabular}{|c|c|c|c|c|c|c|c|c|c|c|c|c|c|c|c|c|}
\hline \multirow[t]{2}{*}{ Year } & \multicolumn{11}{|c|}{$\begin{array}{l}\text { Number of English Language candidates who achieved } \\
\text { these symbols }\end{array}$} & \multicolumn{5}{|c|}{$\%$ of candidates who passed } \\
\hline & * & A & B & C & D & E & $\mathrm{F}$ & G & $u$ & $x$ & Total & $u$ & $x$ & $*-C$ & * $-E$ & $*-G$ \\
\hline 2012 & 0 & 0 & 32 & 382 & 1277 & 850 & 329 & 81 & 30 & 232 & 3213 & $0,9 \%$ & $7 \%$ & $13 \%$ & $79 \%$ & $92 \%$ \\
\hline 2013 & 0 & 0 & 36 & 236 & 868 & 967 & 513 & 187 & 39 & 514 & 3360 & $1 \%$ & $18 \%$ & $10 \%$ & $74 \%$ & $99 \%$ \\
\hline 2014 & 0 & 2 & 21 & 223 & 1321 & 1643 & 642 & 116 & 85 & 1310 & 5363 & $6 \%$ & $2 \%$ & $24 \%$ & $79 \%$ & $98 \%$ \\
\hline
\end{tabular}

Source: BOCODOL 2014

The possible grades a student could achieve ranged from a distinction $\left(^{*}\right)$ up to $\mathrm{X}$; A, $\mathrm{B}$ and $\mathrm{C}$ imply a pass mark above $50 \%$; $\mathrm{D}$ and $\mathrm{E}$ represent a pass mark; F represents those who sat for the examination and failed to achieve the minimum pass mark; $G$ and 
$\mathrm{U}$ represent those who achieved such low grades that they could not even be awarded a mark; X represents students who registered for the examination but did not write it.

The '* - C' category technically represents all candidates who passed. In 2012, only $13 \%$ of the total school equivalency candidature enrolled with BOCODOL was awarded credits for the module; no candidates achieved distinctions, with a drop to a $10 \%$ pass rate in 2013. Despite a significant improvement in 2014 (24\%), these results imply that learners overall do not perform well in their English examination. This possibly affected other subjects too as English is the language of instruction for all subjects. The learners' poor mastery of content led to the following research question regarding the design features of the study materials: To what degree do language issues create barriers to content mastery for secondary school ODL learners enrolled with BOCODOL?

\section{THEORETICAL FRAMEWORK}

Cognitive Load Theory (CLT) relates to cognitive processes and the amount of information that the brain can absorb at any given time. It emphasises the use of examples which can facilitate learners' better understanding of content, especially examples they are familiar with and that relate to their culture, environment and socioeconomic background (Gorsky, Caspi and Smidt 2007). The theory suggests that the brain needs to be assisted in retaining content. Thus, by using fewer and simpler words in narrative text and adding illustrations and cues to explain difficult concepts, learners are better able to grasp the new content. Mnemonics can be used to aid memory and to simplify real-world concepts. Furthermore, if content is chunked into manageable and coherent sections and the learning experience is scaffolded, learners are more readily able to consolidate and internalise the content.

CLT warns that extraneous information complicates the learning experience, and emphasises learning strategies that are informed by learner needs, and assessment that is aligned to the stated learning objectives to check learners' mastery of content. In CLT, emphasis is placed on the need for high levels of learner engagement. For instance, for learners to become proficient speakers of a language, there should be several speaking and listening opportunities for learners to practice these communicative skills while learning the correct pronunciation of words and extending their vocabulary.

Having well-developed cognitive academic language proficiency (CALP) is imperative for academic progress as it enables learners to engage with content at a sophisticated level, especially in tasks that have to be solved independently without help from the context. This type of language proficiency is developed over time in formal academic settings where demonstrations, calculations, explanations and experimentation all form part of the content being taught. The ability to carry out such learning tasks successfully in a second language takes even longer to acquire and does not merely imply an understanding of the content area vocabulary but includes skills such as comparing, classifying, synthesising, evaluating, and inferring (Cummins 1979). 
Content developed using CLT guidelines seeks to engage, rather than tell learners and provides ways to facilitate interaction during the learning process. The importance of learner-content interaction is further emphasised by the Theory of Instructional Dialogue (TID) (Gorsky et al. 2007), which advocates initiating some form of dialogue within the learning context to allow for highly interactive, and engaging study materials. By implication, the designers of ODL study materials need to devise opportunities for learners to interact with one another by creating tasks which encourage such interaction.

\section{RESEARCH DESIGN AND METHODOLOGY}

Our case study was largely informed by the interpretive paradigm espoused by Creswell (2005). We used the nested mixed methods approach to assess the design and development of BOCODOL ODL study materials, and established whether these materials, in any way, acted as barriers to learners' mastering the content and thus making academic progress. The interpretive paradigm allowed us to interact directly with our documents and participants and to deduce and interpret meanings from our observations and data sources. The self-designed protocols included interview guides, questionnaires and document analysis templates, which allowed for multiple data sources. The mixed methods approach enabled thick verbatim descriptions while questionnaires provided quantitative data. Selected study materials served as our chief unit of analysis as we sought to establish whether language could create 'distance' and make access to and mastery of content problematic for learners, thus impeding academic progress.

\subsection{Research Sites}

Three centres (Gaborone Secondary School learning centre, Linchwe Secondary School learning centre and Kaudwane/Diphuduhudu satellite learning centre) fall under the jurisdiction of Gaborone - the capital city of the Republic of Botswana. This region has a well-developed and electrified infrastructure with a high concentration of functional schools, health facilities and telecommunications. ODL learners have easy access to libraries, tutors, network facilities and reliable transport.

Kang Regional Centre is a peri-urban centre along the Trans-Kalahari highway which connects Botswana and Namibia. This second region is 400 kilometres from Gaborone. The region has good internal road networks and postal services. Kang has a community library and two reading rooms, i.e. simple enclosed spaces where one may read in peace. Research sites in this region are Matsha Community College, Gantsi State Prison and Takatokwane Primary School. These sites are considered remote as they are more than forty kilometres from a service centre with adequate amenities. The table below provides a sense of the distance of research sites from Gaborone, where BOCODOL headquarters is situated and where programmes are developed. The research sites are listed according to their distance from Gaborone. 
Table 2: Distance between research sites and Gaborone

\begin{tabular}{|l|l|}
\hline Research site & $\begin{array}{l}\text { Distance from Gaborone } \\
(\mathbf{k m})\end{array}$ \\
\hline Gaborone Secondary School & - \\
\hline Linchwe Secondary School & $35 \mathrm{~km}$ \\
\hline Kaudwane Primary School & $190 \mathrm{~km}$ \\
\hline Takatokwane Primary School & $200 \mathrm{~km}$ \\
\hline Matsha Community College & $400 \mathrm{~km}$ \\
\hline Gantsi State Prison & $700 \mathrm{~km}$ \\
\hline
\end{tabular}

\subsection{Participants and Sampling Criteria}

The participants were drawn from BOCODOL centres in the Kang and Gaborone regions. Five teachers (one male, four female) who had contributed to the development of the study materials under review, six BGCSE English tutors and 176 learners provided us with multiple data sets. The majority of the learners are geographically very isolated and commonly disadvantaged by poor infrastructure and the erratic availability of transport. They lack the necessary amenities at home and have little or no access to study centres, libraries or tutors. Participants were all older than 16 years, the age of consent in Botswana. All relevant ethical considerations were adhered to and the necessary approval was obtained from institutions; participants provided informed, voluntary consent.

The five material developers were all teaching professionals who had contributed to the development of the English Language study material. They were not professionally trained writers or ODL practitioners but were employed as teachers (primary school $=1$; secondary school $=3$ ) or as lecturers $(=1)$ at a tertiary institution. We used non-probability, purposive sampling to select six tutors who had been working with BOCODOL for a minimum of six months. The tutors had interacted with the materials under evaluation long enough to provide the necessary information we needed. They were all employed: one was a primary school teacher, two were teachers at junior secondary schools, two taught at senior secondary schools, while one was employed as a lecturer at a tertiary institution. Of these six tutors, two were male and four were female. A purposive sample of 176 learners selected from the 2009-2014 cohorts permitted us to make a fair analysis of the learners' attitudes towards, and experiences of, using the same BOCODOL ODL study materials, but in varied environments.

\subsection{Data Collection and Analysis}

We developed interview guides and questionnaires that allowed for effective data collection from the material developers, learners and tutors in order to establish their attitudes to and perceptions of the language used in the study material. Before embarking 
on data collection, we piloted the research instruments on material developers, learners and tutors from BOCODOL centres other than the participating sites. This helped to establish whether the research instruments would adequately answer our research question and render the data we intended to collect, and whether the instruments were clear, unambiguous and sufficiently user-friendly. Twenty five learners were interviewed during this feedback exercise. Twenty three of twenty five learner questionnaires were returned. We also invited three tutors and four material developers to respond via a questionnaire. Feedback helped us both to refine our questions and to confirm the adequacy of our research instruments. A document analysis template based on similar ones used by the Commonwealth of Learning and the South African Institute of Distance Education was crafted with an emphasis on the linguistic aspects of the materials.

\subsection{Document Analysis}

We used the twelve BGCSE English Module materials, packaged in the form of booklets, and prepared for learners who are granted two to five years to complete the BGCSE English programme. These materials were commissioned by BOCODOL, who employed subject experts part-time as material developers and assigned them writing and editing roles. These modules and their support material have never been reviewed since their development and initial implementation in 2001.

For learning to take place and for content to be accessed comfortably by learners, the language used should be at an appropriate level and presented in a comprehensible manner. We used Gunning's fog index to determine the ease with which texts could be read and comprehended by learners enrolled for their BGCSE. Based on similar documents, we designed our own material development rubric with specific languagerelated criteria to determine the accessibility and other associated factors of the study material (see Appendix 1).

After repeated readings of the study material using the descriptors and performance indicators from the rubric to analyse the texts, we tabulated and then coded the data using different colours for ease of identification. The analysis included the readability and familiarity of text, illustrations, relevance of language and content, pedagogical principles related to interactivity, teaching strategies used, and the overall userfriendliness of the booklets. Evidence of conformity or lack thereof was also considered using the following scale: 0 : failed to meet criterion; 1 : satisfactory; 2 : marginal; 3 : acceptable; 4: meets all criteria. This helped provide an overall indication of the quality and effectiveness of the study material. From the document analysis, readability, concept clarification, low frequency words, grammatical accuracy, alignment with curriculum, use of illustrations, signposting, content load, and learner profile were identified as codes. Participant feedback was later used to verify data from the document analysis and helped triangulate and validate data sets obtained from the questionnaires and interviews. 


\subsection{Questionnaires}

We developed three questionnaires, one for each group of participants, and used them to establish perceptions and attitudes of learners and tutors regarding the study materials, and the type of training material developers had been provided for the purpose. The questionnaires also addressed general features of the study materials such as the physical layout, and illustrations. The response rate for the learners was $59 \%$ as 176 of the 300 questionnaires sent out were returned as usable. The questionnaires were numbered for management purposes, and there was no record linking specific learners to numbers so as to guarantee and maintain the promised anonymity. Tutors and material developers provided a $100 \%$ response rate. The quantitative analysis was prepared by an institutional statistician who developed a computer report using IBM SPSS, version 22. After receiving the report, we cross-checked all items with the questionnaire to ensure accurate data capturing had taken place.

\subsection{Interviews}

We conducted six face-to-face group interviews that were audio-recorded, and twenty one-on-one interviews across all the research sites. The purpose was to glean an understanding of learner and tutor perceptions of the material supplied for distance learning. Participants responded to questions presented as an interview protocol. This helped maintain uniformity and consistency across the interviews. Learners were much more relaxed during the group interviews but seemed anxious during one-onone sessions. Some struggled to communicate in English and responded very briefly. Participants were encouraged to speak in Setswana in the hope that they would provide a fuller response. However, this did not help much, as the learners remained shy and passive despite English being the official medium of instruction at schools. With the permission of participants, some parts of the interviews were audio and video recorded for transcription purposes. The primary researcher also prepared handwritten field notes in case technical difficulties compromised the recordings.

Twenty learners were interviewed individually while the group interviews each comprised between four and six participants. All twenty learners were exposed to both one-on-one and group interviews. In the Kang region, the indigenous languages of Sesarwa and Sekgalagadi are dominant, yet all participants were comfortable with writing and speaking in Setswana, the national language. The researchers were thus able to fully comprehend responses and an interpreter was not required.

The audio recordings were transcribed by a research assistant and then checked by the primary researcher who finecombed the transcriptions line by line; coding and categorising took place. This phase was followed by data reduction, where data were sorted and selected with a view to presenting or discarding categories. Some examples of codes that emerged from our transcripts included 'irrelevant examples' and 'out- 
dated content'. Data displays served to visually represent findings in a more organised and meaningful format.

\section{FINDINGS AND DISCUSSION}

For the purpose of this article, two emergent themes from our research are discussed below.

\subsection{Inadequacy}

It was apparent that a misalignment between the study materials and the relevant syllabus existed, as several significant sections of the syllabus had not been covered, e.g. listening and speaking skills, report writing, and creative essay writing. Furthermore, the content failed to adequately engage learners and created perceptions of learner isolation. Material developers ought to have theoretically underpinned the material and ensured that a 'conversational' voice was infused in the study materials. Learners were also not able to confirm whether their answers were right or wrong as no feedback or answer key was provided.

Learners, together with material developers and tutors, commented on the many foreign concepts and examples.

Language scaffolding was seriously lacking. No glossary of difficult concepts or technical terms was provided. Instead, learners were told to find out the meanings for themselves. Sentences were complex and lengthy despite the material developers' belief that they had used simple English. There was also little evidence of low frequency words being used, which possibly clarifies why learners claimed that the content was easy, yet they could not understand it fully (Diana and Reder 2006). Verbal signposting was also lacking. Furthermore, materials developers had included instructions and texts without checking the readability index. Some passages were too simple and others too difficult, as evidenced by a fog index ranging between 10 and 14 for the samples drawn from several modules. The following extract was calculated at 14.2:

[T] he use of your imagination can help you to write effectively and creatively, and therefore, to arouse interest in the reader. But you must be clear and to the point in your essay writing. You must be able to communicate through the language you use. How do you use language to write creatively? Well, dear Learner, the language you use depends on the audience (the people you are writing for) or on the purpose of your piece of writing. You should be able to identify suitable language to fulfil a particular function or purpose and you must note the difference between formal and informal language.

For this academic level, passages ought to have measured in the region of 12 , especially if learners are not studying in their native language.

Finally, the meagre training that both material developers and tutors received suggested that they were under-prepared for their roles and responsibilities and that 
a closer collaboration between these key role-players may have enriched the learning experience for all. Inadequate quality control of the final product is a problem which the institution must address without delay. Improving quality measures and engaging experienced instructional designers to drive the development process in conjunction with specialist teachers and tutors ought to address these inadequacies.

\subsection{Imprecision}

One of the core principles of instructional design that the material developers did not take into account is having a sound knowledge of the target audience for whom materials are prepared. The materials did not take cognisance of the diversity of ODL learners but considered them a homogenous group proficient in English and familiar with urban socio-economic lifestyles. They failed to address the remote context in which the majority of BGCSE learners live.

An example of this is when learners were asked to write about 'A dangerous journey by motorbike' and read passages about soccer teams (Manchester United) and experiences in shopping malls or supermarkets. This mismatch between learners' frame of reference or their prior learning and what they were being expected to master did little to facilitate their academic progress. In some cases, materials were outdated e.g. a reference to a beauty queen from a previous decade.

On the technical front, many typographic errors were identified and generally the lay-out was not user-friendly. Illustrations were of poor quality and did not complement the text or enhance understanding. Learners were not guided in terms of how much time they needed to complete a particular learning task nor were icons used as visual signposting. Interview data indicated that learner expectations were not met in terms of what ODL could and should offer.

\section{CONCLUSION}

Our initial hypothesis that the design and development of instructional materials may prevent ODL learners from fully mastering content and thus achieving eventual academic success has been confirmed. It would be prudent, however, not to place all blame for the 'distance' created on language issues. Although the English proficiency of the learners has not been fully developed, this cannot be isolated as the compounding variable. A combination of several other factors added to the isolation and at times, confusion that learners experienced. This instructional dissonance (Evans 2006) highlights the necessity for a robust policy for quality assurance of ODL study materials that are inclusive and accessible in terms of the language of instruction and contain relevant, coherent content which is founded on pedagogically sound principles and underpinned by theory. Further research needs to be conducted on how the English language proficiency of both tutors and learners can be improved through ODL materials. 
In Botswana, studying via distance learning is a feasible option in terms of infrastructure and government support. Well-designed and relevant materials produced in user-friendly language and format could certainly shorten the distance and ease access to qualifications, and thus contribute to the country's vision of an educated citizenry despite vast remote and arid areas characteristic of this African country.

\section{REFERENCES}

BOCODOL. 2010/2011. Enrolment Statistics provided by the Office of the Registrar.

BOCODOL. 2014. Academic Registry Examination Report provided by the Office of Registrar.

Chebanne, M., and L. Nyathi-Ramahobo. 2003. Language use and language knowledge in Botswana. Paper presented at the CSO: 2001 Population and Housing Census Dissemination Seminar. Gaborone, September 8-11, 2003.

Creswell, J. W. 2005. Educational Research: Planning, conducting and evaluating Qualitative and Quantitative Research. Upper Saddle River: Merril.

Cummins, J. 1979. Cognitive/academic language proficiency, Linguistic interdependence, the optimum age question and some other matters. Working Papers on Bilingualism 19: 121-129.

Diana, R. A., and L. M. Reder. 2006. The low-frequency encoding disadvantage: Word frequency affects processing demands. Journal of Experimential Psychology: Learning, Memory, and Cognition 32(4): 805-815.

Evans, R. 2006. The impact of presenters' speech personality on interaction during televised instruction. Journal for Language Teaching 40(2): 21-34.

Gatsha, G. 2010. Learning Support: Perceptions and experiences of remote distance learners from marginalised communities in Botswana. PhD thesis, University of Pretoria.

Gorsky, P., A. Caspi, and S. Smidt. 2007. Use of instructional dialogue by university students in a difficult distance education physics course. Journal of Distance Education 21(3): 1-22.

Indira Ghandi National Open University. 2008. Course ES 319: Language Issues. Study Guide. New Delhi: Indira Ghandi National Open University.

Jotia, A. L., and O. N. Pansiri. 2013. Multicultural education: The missing link in Botswana education policy. European Journal of Educational Studies 5(1): 101-110.

Molosiwa, R. 2009. Botswana Handbook. Gaborone: Government Printers.

Mphinyane, O. P. 1999. What makes materials work? Paper presented at the DFID Workshop, Pretoria, May 1999.

Otukile, O. 2011. Challenges faced by learners in the transition from traditional classroom education to ODL: A case of JC and BGCSE Learners at Botswana College of Distance and Open Learning (BOCODOL). DEASA-SADC CDE International Journal of Open and Distance Learning 4: 61-70.

Phillips, J. A. 2007. Writing self-instructional materials for distance learners: An introspective study. Paper presented at the $21^{\text {st }}$ Asian Association of Open Universities (AAOU) Annual conference, Kuala Lumpur, 29-31 Ocober 2007. 
Reed, Y. 2010. Medaiting Knowledge Constituting Subjectivities in Distance Education Materials for language Teachers in South Africa. PhD thesis, University of the Witwatersrand.

Republic of Botswana. 1977. Education for Kagisano - Revised National Commission on Education. Gaborone: Government Printers.

Republic of Botswana. 1993. Report of the National Commission on Education. Gaborone, Botswana: Government Printers.

Republic of Botswana 1994. Revised National Policy on Education (RNPE). Gaborone, Botswana: Government Printers.

Republic of Botswana. 1997. Presidential task group on a long term vision for Botswana: Towards prosperity for all. Gaborone: Government Press.

Republic of Botswana. 2003. Report of the National Commission on Education. Gaborone, Botswana: Government Printers.

Rowntree, D. 1990. Teaching through self-instruction: How to develop Open Learning Materials. $2^{\text {nd }}$ ed. London: Kogan Page.

Schlosser, C. A., and M. L. Anderson. 1994. Distance education: A review of literature. Ames: Iowa Distance Education Alliance.

Seeletso, M. K. 2011. The structure of ODL Study materials. Paper presented during the induction of BOCODOL new distance education tutors at Francistown, Botswana.

Seeletso, M. K. 2015. The design of instructional materials as a potential contributor to academic success for secondary school open and distance learners in Botswana. PhD thesis, University of Pretoria.

Sibomana, W. 2014. The role of distance education materials in addresisng the professional development needs of high school teachers in Rwanda. PhD thesis, University of Witwatersrand.

Stewart, C., and T. L. Lopes. 2015. Higher education in Brazil: Determinant factors at distance learning. European Academic Research 2(11): 14981-14991. 
Appendix 1: Analysis of materials rubric - Botswana College of Distance and Open Learning BGCSE English Study modules

Guide: 0 -Fails to meet criterion 1 - Unsatisfactory 2-Marginal 3-Accepted 4-Meets all criteria

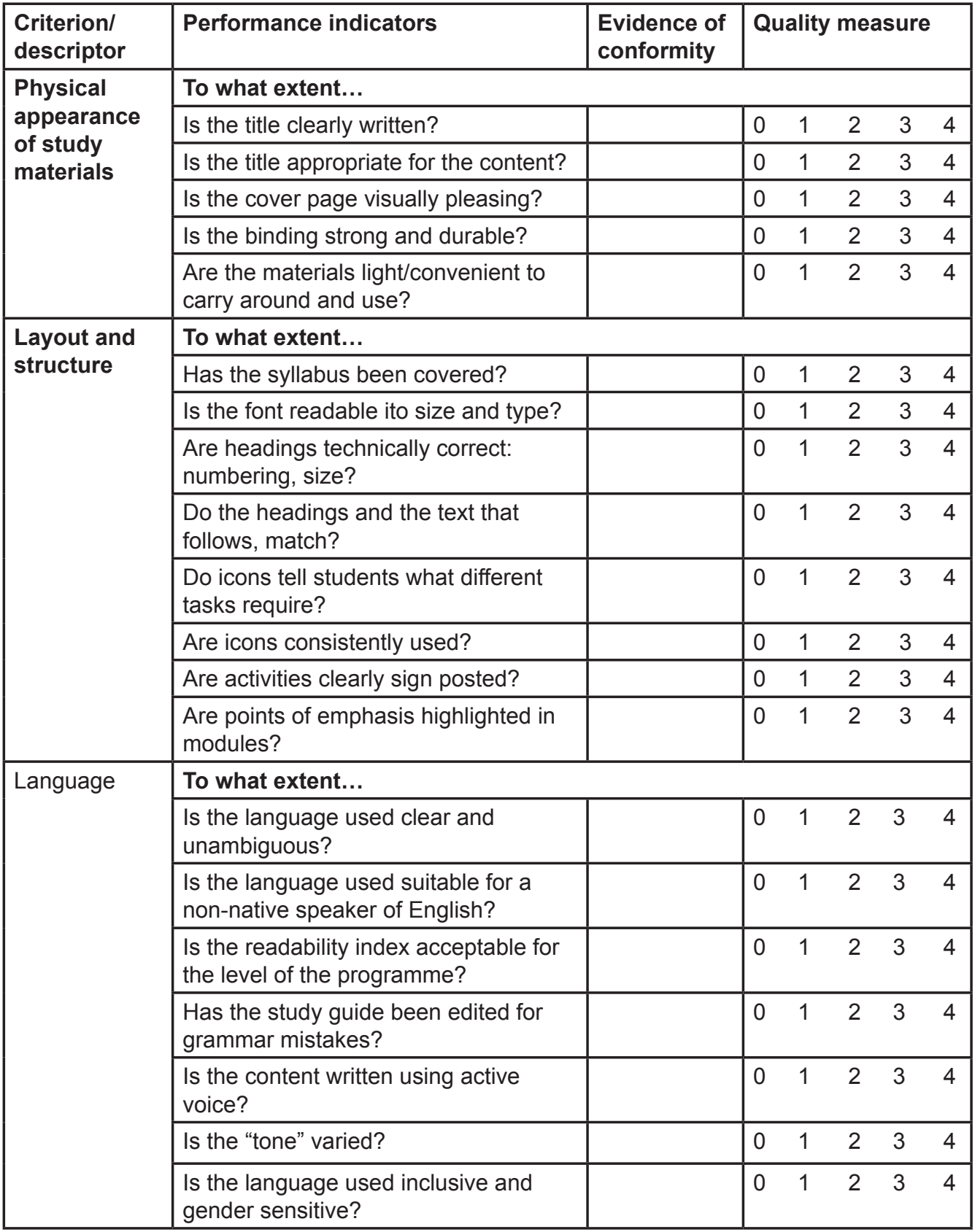




\begin{tabular}{|c|c|c|c|c|c|c|}
\hline \multirow[t]{7}{*}{ Content } & \multicolumn{6}{|l|}{ To what extent... } \\
\hline & $\begin{array}{l}\text { Is the content aligned with the national } \\
\text { curriculum?? }\end{array}$ & 0 & 1 & 2 & 3 & 4 \\
\hline & $\begin{array}{l}\text { Is the content overloaded for the } \\
\text { BGCSE level? }\end{array}$ & 0 & 1 & 2 & 3 & 4 \\
\hline & $\begin{array}{l}\text { Are new concepts and terms } \\
\text { highlighted in the text? }\end{array}$ & 0 & 1 & 2 & 3 & 4 \\
\hline & $\begin{array}{l}\text { Are concepts explained using relevant } \\
\text { examples? }\end{array}$ & 0 & 1 & 2 & 3 & 4 \\
\hline & $\begin{array}{l}\text { Is new knowledge linked to learners' } \\
\text { existing knowledge? }\end{array}$ & 0 & 1 & 2 & 3 & 4 \\
\hline & $\begin{array}{l}\text { Does a glossary explaining all new } \\
\text { concepts and terms? }\end{array}$ & 0 & 1 & 2 & 3 & 4 \\
\hline \multirow[t]{5}{*}{ Illustrations } & \multicolumn{6}{|l|}{ To what extent... } \\
\hline & $\begin{array}{l}\text { Are illustrations self-explanatory and } \\
\text { understandable? }\end{array}$ & 0 & 1 & 2 & 3 & 4 \\
\hline & $\begin{array}{l}\text { Are illustrations used as pedagogical } \\
\text { tools? }\end{array}$ & 0 & 1 & 2 & 3 & 4 \\
\hline & $\begin{array}{l}\text { Do illustrations clarify/complement the } \\
\text { text? }\end{array}$ & 0 & 1 & 2 & 3 & 4 \\
\hline & $\begin{array}{l}\text { Are illustrations acceptable its size, } \\
\text { quality, and cultural-sensitivity? }\end{array}$ & 0 & 1 & 2 & 3 & 4 \\
\hline \multirow{6}{*}{$\begin{array}{l}\text { Teaching } \\
\text { strategies } \\
\text { that facilitate } \\
\text { interactivity }\end{array}$} & \multicolumn{6}{|l|}{ To what extent... } \\
\hline & $\begin{array}{l}\text { Do the materials integrate ICT to } \\
\text { facilitate learning? }\end{array}$ & 0 & 1 & 2 & 3 & 4 \\
\hline & $\begin{array}{l}\text { Are ICT advances used relevant to the } \\
\text { text? }\end{array}$ & 0 & 1 & 2 & 3 & 4 \\
\hline & $\begin{array}{l}\text { Is a learner-centred approach used? Is } \\
\text { independent learning encouraged? }\end{array}$ & 0 & 1 & 2 & 3 & 4 \\
\hline & $\begin{array}{l}\text { Do teaching strategies incorporate } \\
\text { diversity? }\end{array}$ & 0 & 1 & 2 & 3 & 4 \\
\hline & $\begin{array}{l}\text { Are materials interactive enough to } \\
\text { break learner isolation? }\end{array}$ & 0 & 1 & 2 & 3 & 4 \\
\hline
\end{tabular}




\begin{tabular}{|c|c|c|c|c|c|c|}
\hline \multirow{11}{*}{$\begin{array}{l}\text { User } \\
\text { friendliness }\end{array}$} & \multicolumn{6}{|l|}{ To what extent... } \\
\hline & $\begin{array}{l}\text { Have authors been profiled in the } \\
\text { study material? }\end{array}$ & 0 & 1 & 2 & 3 & 4 \\
\hline & $\begin{array}{l}\text { Is the reader oriented in terms of } \\
\text { course content? }\end{array}$ & 0 & 1 & 2 & 3 & 4 \\
\hline & $\begin{array}{l}\text { Have objectives/outcomes per } \\
\text { section been provided? }\end{array}$ & 0 & 1 & 2 & 3 & 4 \\
\hline & $\begin{array}{l}\text { Is a time allocation indicated for } \\
\text { completing tasks? }\end{array}$ & 0 & 1 & 2 & 3 & 4 \\
\hline & $\begin{array}{l}\text { Are units presented in } \\
\text { manageable chunks? }\end{array}$ & 0 & 1 & 2 & 3 & 4 \\
\hline & $\begin{array}{l}\text { Is immediate feedback provided } \\
\text { to in-text activities? }\end{array}$ & 0 & 1 & 2 & 3 & 4 \\
\hline & $\begin{array}{l}\text { Are examples used relevant to } \\
\text { the learners' diverse contexts? }\end{array}$ & 0 & 1 & 2 & 3 & 4 \\
\hline & $\begin{array}{l}\text { Does content lend itself to } \\
\text { collaborative work? }\end{array}$ & 0 & 1 & 2 & 3 & 4 \\
\hline & $\begin{array}{l}\text { Are the learners provided with list } \\
\text { for further reading? }\end{array}$ & 0 & 1 & 2 & 3 & 4 \\
\hline & $\begin{array}{l}\text { Is the student addressed directly } \\
\text { in the } 2^{\text {nd }} \text { person (you)? }\end{array}$ & 0 & 1 & 2 & 3 & 4 \\
\hline \multirow[t]{9}{*}{ Assessment } & \multicolumn{6}{|l|}{ To what extent... } \\
\hline & $\begin{array}{l}\text { Are self-assessment activities } \\
\text { (SAA) provided? }\end{array}$ & 0 & 1 & 2 & 3 & 4 \\
\hline & $\begin{array}{l}\text { Is feedback provided in the } \\
\text { text (e.g. answer keys, tutor } \\
\text { comments)? }\end{array}$ & 0 & 1 & 2 & 3 & 4 \\
\hline & $\begin{array}{l}\text { Does feedback help learners } \\
\text { identify their mistakes/ } \\
\text { misconceptions? }\end{array}$ & 0 & 1 & 2 & 3 & 4 \\
\hline & $\begin{array}{l}\text { Are assessment items varied to } \\
\text { maintain interest? }\end{array}$ & 0 & 1 & 2 & 3 & 4 \\
\hline & $\begin{array}{l}\text { Is the formulation of the } \\
\text { assignments well-scaffolded? }\end{array}$ & 0 & 1 & 2 & 3 & 4 \\
\hline & $\begin{array}{l}\text { Is constructive alignment evident } \\
\text { in the materials? }\end{array}$ & 0 & 1 & 2 & 3 & 4 \\
\hline & $\begin{array}{l}\text { Are assignments to be tutor- } \\
\text { marked (TMA) provided with the } \\
\text { material? }\end{array}$ & 0 & 1 & 2 & 3 & 4 \\
\hline & Is the tutor feedback supportive? & 0 & 1 & 2 & 3 & 4 \\
\hline
\end{tabular}

